\title{
EFFECTS OF OPENING LOCATION ON FLEXURAL BEHAVIOR OF RC COLUMNS WITH SIDEWALLS
}

\author{
Daisuke Kato $^{1}$, Daisuke Sato ${ }^{2}$ and Tadashi Takamatsu ${ }^{3}$
}

(Submitted February 2017; Reviewed June 2017; Accepted October 2017)

\begin{abstract}
Practical use of secondary walls such as sidewalls is common because the contributions of secondary walls for stiffness or strength have been recognized. In 2016, "AIJ Standard for Lateral Load-carrying Capacity Calculation of Reinforced Concrete Structures" was published as a draft by Architectural Institute of Japan. In this standard new equations for columns with side walls were proposed. From this viewpoint, the authors have conducted static loading tests of flexurally controlled RC column specimens with single opening in the sidewall, to investigate the effects of openings on strength and deformation capacity of RC columns with a side walls. In this paper, the limitations on location of openings inside sidewalls to avoid their effects on flexural strength and deformation capacity are examined using design equations for flexural strength based on full plastic moment of the column and sidewall. The test results indicate that the proposed limitation line on location of openings to avoid their effects for flexure could be effective for practical design.
\end{abstract}

\section{INTRODUCTION}

Practical use of secondary walls such as sidewalls is expected in building construction in Japan because contributions of secondary walls for stiffness or strength have been recognized. However suitable design equations for secondary walls had not been provided. From this view point some studies were conducted and as a result of these studies new equations for columns with side walls were proposed in "AIJ Standard for Lateral Load-carrying Capacity Calculation of Reinforced Concrete Structures" published as a draft by Architectural Institute of Japan in 2016 [1].

This standard was developed using static loading tests of RC column specimens with unperforated sidewalls failing in shear and flexure. However, small openings are popularly set up on sidewalls for the purpose of plumbing, heating, electric installations, etc. From this view point authors have conducted static loading tests of RC column specimens with a perforated side wall failing in shear and examined effects of openings on shear strength [2].

Previous work was also conducted static loading tests of RC column specimens with a perforated sidewall failing in flexure and examined effects of openings on flexural strength and deformation capacity of RC columns with a side wall [3-5]. The objectives of the studies were to make clear the effects of openings on performance of members. In this paper the limitation on location of openings to avoid their effects was examined. In other words the locations of openings were examined so that perforated sidewalls demonstrated the same flexural performance as unperforated sidewalls.

\section{OUTLINE OF TEST}

Concepts of Effects of Openings on Flexural Strength and Ultimate Deformation

In this study, the limitation on location of openings to avoid their adverse effects was examined first. In other words, the locations of openings were examined so that perforated sidewalls exhibited the same flexural performance as unperforated sidewalls. For this purpose two kinds of flexural strength were introduced, i.e. flexural strength of columns with unperforated sidewalls (without openings) and flexural strength of columns with perforated sidewalls.

Figure 1a shows the concept of flexural strength of columns with unperforated sidewalls. In this case, flexural strength $Q_{w}$ (Eq. 2) can be calculated using a simplified theoretical equation based on full plastic moment. On the other hand, Figure $1 \mathrm{~b}$ shows the concept of flexural strength of columns with perforated sidewalls. The flexural strength can be evaluated as the minimum value of two strengths $\left(Q_{w}\right.$ (Eq. 2) and $Q_{w o}(y, z)$ (Eq. 4). Here, $M_{w}$ (Eq. 3) represents moment strength of unperforated column with sidewalls and $M_{w o}(y)$ (Eq. 5) represents moment strength determined by the section just under the opening.

Using these two strengths the location of openings where openings have effects on flexural strength can be estimated using Eq. 1. If opening length $\left(l_{o}\right)$ and the location $(y, z)$ are given, the flexural strength with opening $Q_{w o}(y, z)$ can be obtained. Where, $y$ and $z$ represent the coordinate of the rightbottom corner as shown in Figure 1c. The triangle portion (the width and height of which are $y_{o}$ and $z_{o}$ ) of the sidewall in Figure 1c represents the area where $Q_{w}$ is larger than $Q_{w o}(y, z)$. In other word if the right-bottom corner of the opening is located inside this triangle portion, the flexural strength decreases comparing to unperforated member due to the opening. So, this is called the area where openings have effects on flexural strength.

$Q_{w}>Q_{w o}(y, z)$

$Q_{w}=\frac{M_{w}}{H}$

$M_{w}=\left(T_{C}+\frac{T_{R}}{2}+N\right) \cdot\left(\frac{D}{2}+l_{R}-\frac{x_{o}}{2}\right)+T_{L} \cdot\left(\frac{l_{L}}{2}+D+l_{R}-\frac{x_{o}}{2}\right)$

\footnotetext{
1 Prof., Dr. Eng., Dept. of Architecture and Civil Engineering, Faculty of Engineering, Niigata University,dkato@eng.niigata-u.ac.jp

2 Graduate Student, Graduate School of Science and Technology, Niigata University, f13e039g@mail.cc.niigata-u.ac.jp

3 Graduate Student, Graduate School of Science and Technology, Niigata University, f15e046j@mail.cc.niigata-u.ac.jp
} 
$Q_{w o}(y, z)=\frac{M_{w o}(y)}{H-z}$

$M_{w o}(y)=\left(T_{c}+\frac{T_{R}}{2}+N\right) \cdot\left(\frac{D}{2}+l_{R}-j_{c}\right)+T_{L} \cdot\left(\frac{l_{L}}{2}+D+l_{R}-j_{c}\right)$

$x_{o}=\frac{N+T_{L}+T_{C}+\frac{T_{R}}{2}}{k \cdot \sigma_{p} \cdot t}$

$j_{c}=\frac{1}{x_{o}}\left\{\left(x_{o}-y\right) \frac{\left(x_{o}+2 l_{o}+y\right)}{2}+y \frac{y}{2}\right\}$

where, $T_{L}$ and $T_{R}$ are the total tensile yielding force of all longitudinal reinforcing bars of left and right sidewalls, respectively. Note that the total tensile yielding force $T_{R}$ is assumed to be half of yielding force of all longitudinal reinforcing bars of left side for simplicity. $T_{C}$ is the total tensile yielding force of all longitudinal reinforcing bars of the column and $N$ is axial force subjected to the center of the column. Also the resultant compression force of concrete $(C$ in Figures1(a)(b)) is always assumed to act at the centroid of the stress blocks, which means that it acts at the center of stress block $\left(x_{0} / 2\right)$ in case of unperforated sidewalls and it acts at the centroid $\left(j_{c}\right.$, Eq. 7) of two stress blocks in case of perforated sidewalls. Symbol $\sigma_{p}$ is the concrete compressive strength and $k$ is the coefficient of concrete strength used for equivalent compression stress block and assumed to be 0.85 . Other symbols are shown in Figure 1.

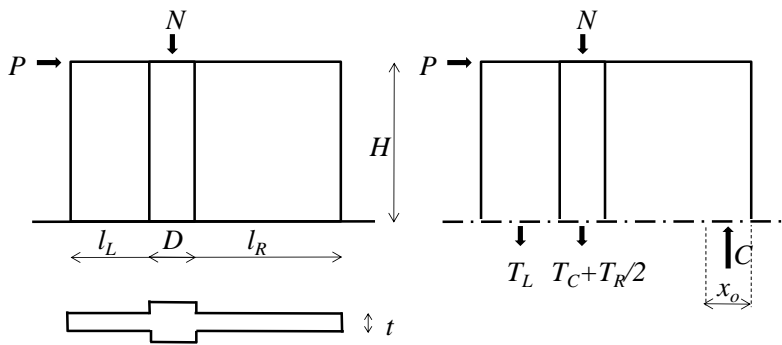

(a) Flexural strength of wall without openings

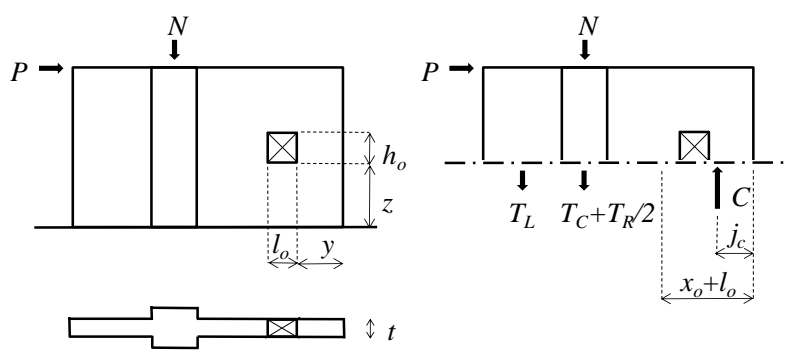

(b) Flexural strength of wall with openings

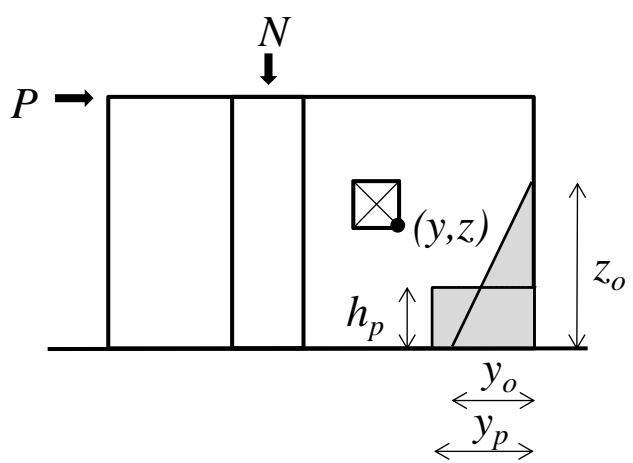

(c) Location of openings where openings have an effect

Figure 1: Flexural strengths and location of openings, which have an effect on flexural strength and ultimate deformation.
Equalizing $Q_{w}$ with $Q_{w o}(y, z)$ in Eq. 1, the relationship between $y$ and $z$ can be expressed by a linear equation. The vertical intercept coordinate $z_{o}$ and the horizontal intercept $y_{o}$ are expressed by Eqs. 8 and 9, respectively. Consequently, the gray triangle zone in Figure 1(c) represents the area where openings affect the flexural strength.

$z_{o}=H\left(1-\frac{M_{w o}(0)}{M_{w}}\right)$

$y_{o}\left(=x_{o}\right)=\frac{T_{L}+T_{C}+\frac{T_{R}}{2}+N}{k \cdot \sigma_{p} \cdot t}$

On the other hand, after flexural strength this triangle zone will expand because compressive failure of concrete occurs not only at the critical section but also inside the member around the critical section. From this view point neutral axis depth of compressive concrete $\left(y_{o}=\left(x_{0}\right)\right)$ was assumed to expand to $y_{p}$ and keep constant inside some height $\left(h_{p}\right)$ from the critical section as shown in Figure 1c. Note values of $y_{p}$ and $h_{p}$ are discussed and determined experimentally in Section 3 in this paper. Finally, the gray zone in Figure 1c represents the area where openings have effects on flexural strength and ultimate deformation. Namely if the right-bottom corner of the opening is located inside this gray zone, the flexural strength will decrease comparing with unperforated sidewall.

\section{Outline of Test Specimens}

Experimental studies had been reported in Refs. [3-5] using reinforced concrete columns with a perforated sidewall failing in flexure to examine the effects of openings on flexural strength and deformation capacity of columns with sidewalls. The target of this test series was to get the limitation on location of openings to avoid their effects. Table 1 shows characteristics of test specimens and material strength. Eight specimens were tested. The scale of the specimens was about one third of practical buildings. Seven of them were specimens with one perforated side wall. The size of openings was not large because the openings of sidewalls represent plumbing, heating or electric installations, etc as mentioned before. The reduction factor $r$ for shear strength shown later in Figure $6 \mathrm{c}$ was about 0.8. Columns, wall reinforcement, size of opening, axial load and cantilever loading were the same for all specimens. Wall thickness, confinement of end of the wall and shear span ratio were varied, with the main variables being the location of openings.

Figure 2 shows the reinforcing arrangement of specimens. The wall thickness of specimens F-D and F-U was $75 \mathrm{~mm}$. And that of others was $100 \mathrm{~mm}$. The concrete of the edge portion of sidewalls of specimens F-100MC and F-100MC-1800 were confined by tie reinforcement as shown in the figure. Note that unperforated specimen $\mathrm{F}$ represented reused specimen set upside down after repair, which had been tested as F-100M. Right figure of Figure $2 \mathrm{~g}$ shows crack patterns and the repaired portion of specimen F-100M after scheduled loading made upside down.

Figure 3 shows loading set up. For all specimens cantilever type loading was used. Specimens were subjected to constant axial load by two vertical jacks and lateral load reversals were applied at the top of the upper girder of the specimen, the height of which was $1300 \mathrm{~mm}$ from the critical section of the specimen. Note that additional moment was applied to specimens by two vertical jacks, which lead to the enhancement of shear span from $1400 \mathrm{~mm}$ to $1800 \mathrm{~mm}$ (shear span ratio was from 1.87 to 2.0). Note that out-of-plane drift was restricted by out-of-plane roller supports in this testing equipment. 

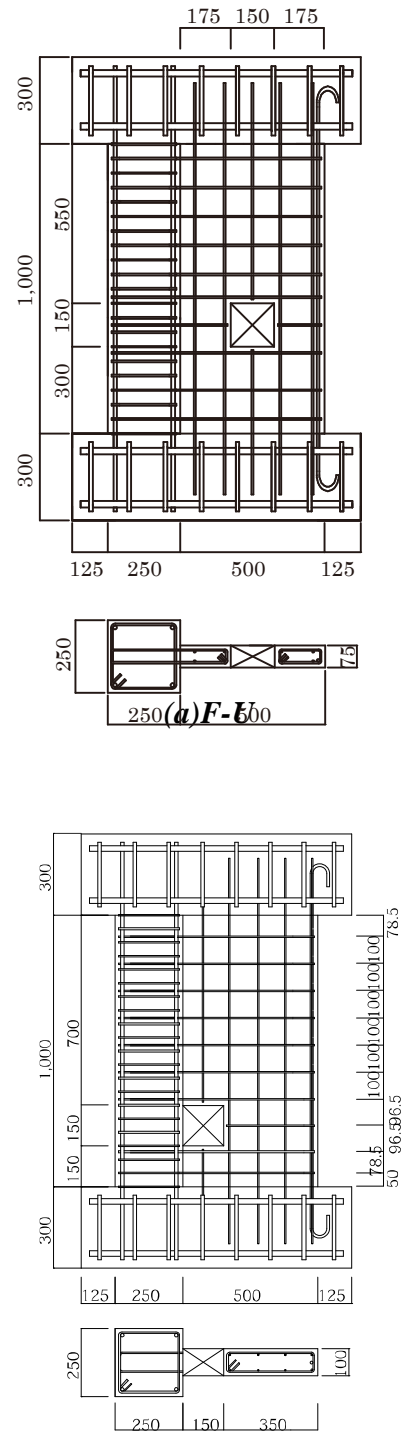

(e)F-100M
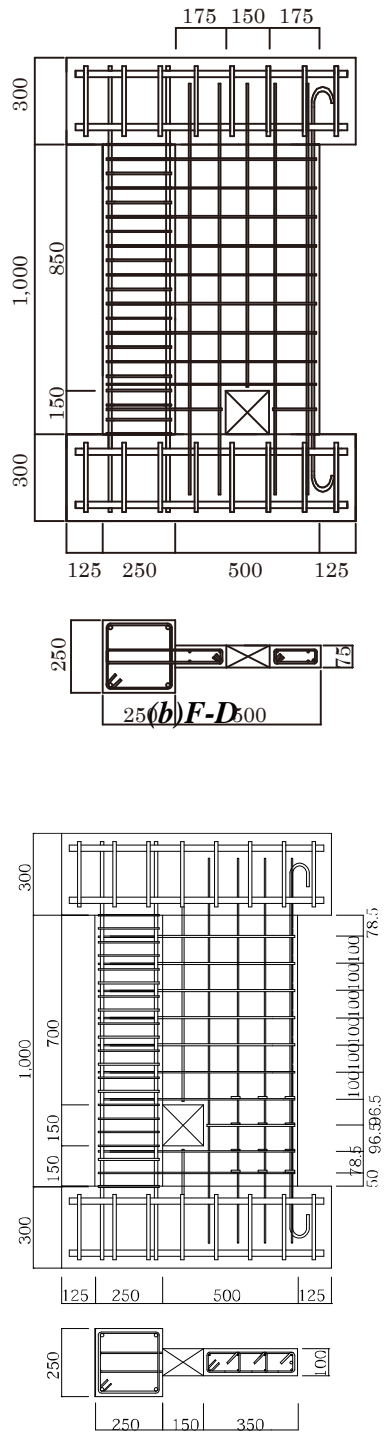

(f)F-100MC

\section{F-100MC-1800}
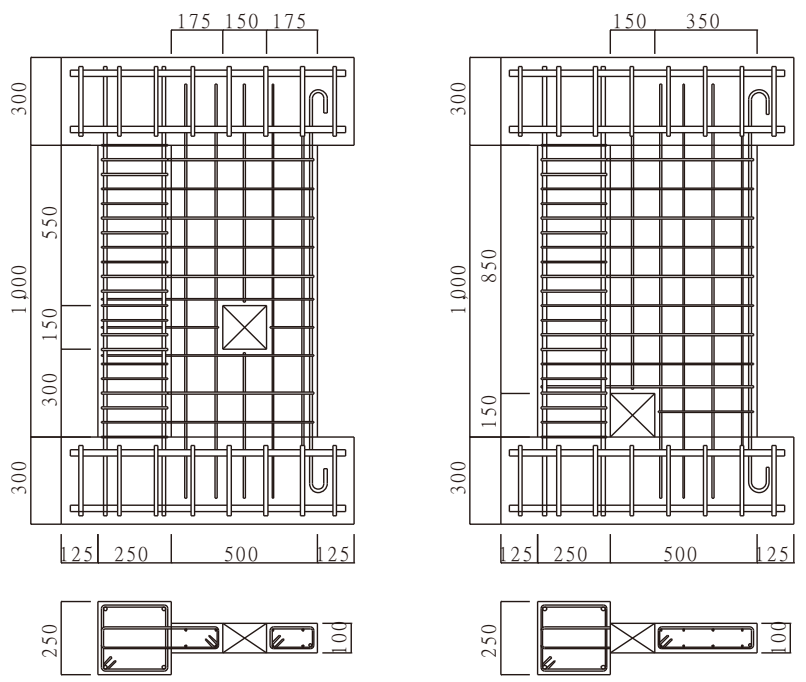

(c) $\mathrm{F}-100 U$

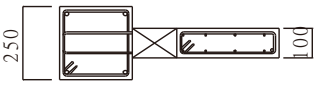

(d)F-100D
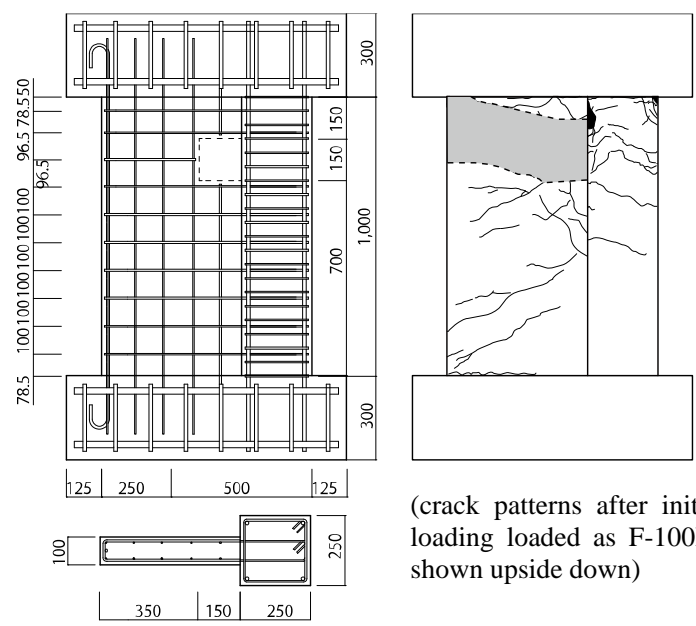

(crack patterns after initial loading loaded as F-100M, shown upside down)

(g)F (reused specimen of F-100M)

Figure 2: Reinforcement arrangement.

\section{OUTLINE OF TEST RESULTS OF COLUMNS WITH A SIDEWALL FAILING IN FLEXURE}

Figures 4a-h show lateral load-lateral drift relation of specimens. In Figure 4 calculated flexural strength obtained using equations shown in Eq. 1 and observed ultimate deformation which was defined as the drift angle when the restoring force of the specimen degraded to $80 \%$ of the maximum strength are also shown. These specimens showed similar behavior with specimens failing in shear from the view point such as the restoring force degraded rapidly after maximum strength, and after the rapid degradation of restoring force stable behavior which represented the behavior of column only can be seen. It must be noted that the restoring force degraded rapidly in case of specimens with unconfined sidewall (F-D, F-U,F-100U, F-100D and F-100M) whereas the restoring force degraded more gently in case of confined specimens (F-100MC and F-100MC-1800).

On the other hand Table 2 shows observed failure mechanism of concrete and bars of sidewalls. Buckling of longitudinal reinforcing bars in sidewalls of all specimens were observed. After buckling the rupture of these bars were observed in all specimens except for specimen F-U. Note that out of plane drift was not observed because the drift to outside of was restricted as shown before.

Right figure of Figure $4 \mathrm{~h}$ shows the relationship between drift angle and the neutral axis depth which was estimated using two displacement transducers set at the both edge of the bottom section (the measuring length of these transducers was $175 \mathrm{~mm}$ from the bottom section) of unperforated specimen $\mathrm{F}$ in the positive loading direction. Note that only data of drift angle more than $0.002 \%$ was plotted. The figure indicates the minimum depth was $375 \mathrm{~mm}$ and the depth observed at the ultimate deformation was $437 \mathrm{~mm}$. In this study openings set inside neutral axis depth at the ultimate deformation were assumed to have effects on flexural strength and deformation capacity. In other words $y_{p}$ in Figure $1 \mathrm{c}$ was assumed to be $437 \mathrm{~mm}$, which lead to the value of $k_{p}$ as shown in Eq. 10 using Eq. 9.

$k_{p}=0.6$ 
Table 1: Properties of specimens and material strength.

\begin{tabular}{|c|c|c|c|c|c|c|c|c|c|c|c|}
\hline \multicolumn{4}{|c|}{ specimen name } & F-U & F-D & F-100U & F-100D & F-100M & F-100MC & F-100MC-1800 & $\mathrm{F}$ \\
\hline \multicolumn{4}{|c|}{ height of column and side wall (mm) } & \multicolumn{8}{|c|}{1000} \\
\hline \multicolumn{4}{|c|}{ shear span length (mm) } & \multicolumn{4}{|c|}{1500} & \multicolumn{2}{|c|}{1400} & 1800 & 1400 \\
\hline \multicolumn{4}{|c|}{ (shear span ratio, M/VL) } & \multicolumn{4}{|c|}{$(2.0)$} & \multicolumn{2}{|c|}{$(1.87)$} & $(2.4)$ & $(1.87)$ \\
\hline \multirow{3}{*}{ column } & \multicolumn{3}{|c|}{ section $(\mathrm{mm} \times \mathrm{mm})$} & \multicolumn{8}{|c|}{$250 \times 250$} \\
\hline & \multicolumn{3}{|c|}{ main bar } & \multicolumn{8}{|c|}{ 4-D13 (SD345) } \\
\hline & \multicolumn{3}{|c|}{ hoop (ratio,\%) } & \multicolumn{8}{|c|}{$\square$-D6@50 (0.51\%) } \\
\hline \multirow{5}{*}{ side wall } & \multicolumn{3}{|c|}{ section $(\mathrm{mm} \times \mathrm{mm})$} & \multicolumn{2}{|c|}{$75 \times 500$} & \multicolumn{6}{|c|}{$100 \times 500$} \\
\hline & \multicolumn{3}{|c|}{ reinforcement (ratio, $\%)$} & \multicolumn{2}{|c|}{ D6@ 100 double $(0.85 \%)$} & \multicolumn{6}{|c|}{ D6@ 100 double $(0.64 \%)$} \\
\hline & \multicolumn{3}{|c|}{ edge bar } & \multicolumn{8}{|c|}{ 1-D10 (SD345) } \\
\hline & \multirow{2}{*}{\begin{tabular}{|c|} 
confining \\
ratio $(\%)$
\end{tabular}} & \multicolumn{2}{|l|}{ plane } & \multicolumn{5}{|c|}{-} & \multicolumn{2}{|c|}{$2 \times 32 / 100 / 100=0.64(\%)$} & - \\
\hline & & \multicolumn{2}{|c|}{ orthogonal } & \multicolumn{4}{|c|}{-} & & \multicolumn{2}{|c|}{$5 \times 32 / 350 / 100=0.46(\%)$} & - \\
\hline - & & $\mathrm{nm} \times \mathrm{mm})$ & & & & & 150 & 50 & & & \\
\hline opening & & cartion & & center upper & center down & center upper & side down & & side upper & & - \\
\hline & axial fo & $(\mathrm{kN})$ & & & & & & & & & \\
\hline & oncrete stre & $\mathrm{h}\left(\mathrm{N} / \mathrm{mm}^{2}\right)$ & & 2 & & 22 & & & 24.8 & & 24.8 \\
\hline & & h (strain) & D6 & $391(0$ & $023 \%)$ & $403(0$ & $24 \%)$ & & $403(C$ & $.025 \%)$ & \\
\hline & yierd ste & (strain) & Do & & & 54 & & & 552 & $(29 \%)$ & \\
\hline steel & & & D10 & $373(0$ & $023 \%)$ & $383(0$ & $21 \%)$ & & $389(0$ & $.022 \%)$ & \\
\hline Stect & & oth (strain) & Div & & $(-)$ & 54 & & & 543 & $(28 \%)$ & \\
\hline & ICputure st & or & $\mathrm{D} 13$ & $390(0$ & $022 \%)$ & $378(0$ & $21 \%)$ & & $371(0$ & $.021 \%)$ & \\
\hline & & & D13 & & $(-)$ & 528 & & & 543 & $(29 \%)$ & \\
\hline
\end{tabular}

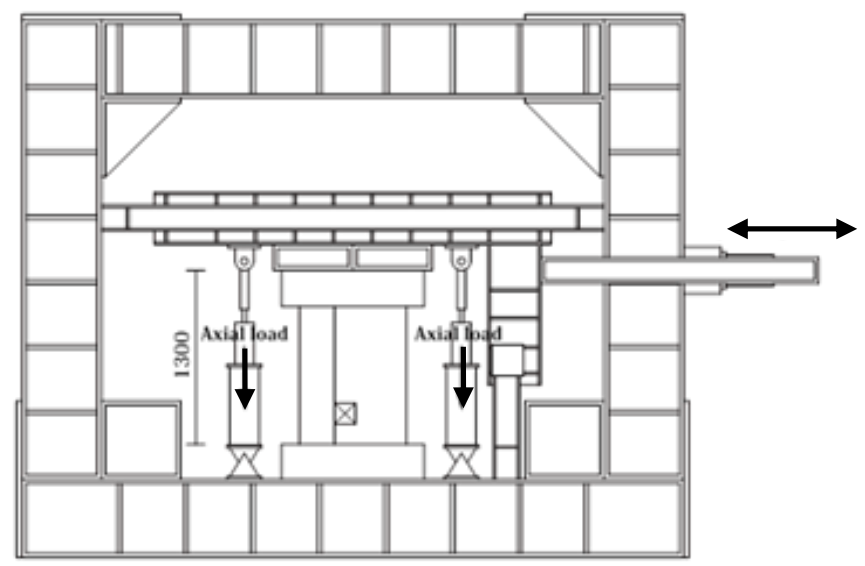

(Loading set up) (deformation distribution)

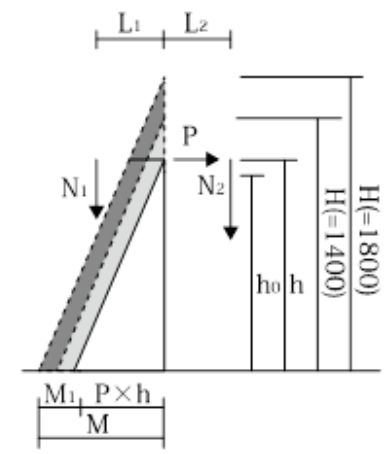

(moment distribution)

Figure 3: Loading set up (cantilever).

Figures 5a-h show crack patterns at maximum strength, ultimate deformation and after loading. In all specimens compressive failure of concrete was observed only at the edge region of sidewall at the maximum strength. And crack patterns oriented compressive zone indicating similar to the unperforated sidewall. In specimen F-U and F-100U compressive failure of concrete extended toward the rightbottom corner of the opening at the ultimate deformation. In other specimens compressive failure of concrete extended overall the sidewalls indicating some effects on deformation capacity.

In Figures 5a-h boundary lines of areas where openings have effects on flexural strength and deformation capacity shown in Figure $1 \mathrm{c}$ are drawn. Equations 8 and 9 were used to estimate the triangle zone $\left(x_{o}, y_{o}\right)$ and $y_{p}$ was estimated by Eq. 9 replacing $k$ by $k_{p}$ shown as Eq. 10. Although height of compressive zone of concrete $h_{p}$ was difficult to estimate, it was estimated referring to failure patterns at ultimate deformation of unperforated specimen $\mathrm{F}$ shown in the middle figure of Figure 5(h), which indicated the height of compressive zone $h_{p}$ was roughly $280 \mathrm{~mm}$. It must be noted that the value $280 \mathrm{~mm}$ must be translated to apply to specimens with other wall thickness because the height of compressive zone possibly depends on wall thickness according to the basic idea of Eq. 15 to evaluate deformation capacity shown later. From this view point Eq. 11 was used to estimate the height of compressive zone $h_{p}$.

$h_{p}=2.8 t$ 


\section{EFFECTS OF OPENINGS ON FLEXURAL STRENGTH AND DEFORMATION CAPACITY OF COLUMNS WITH SIDEWALLS}

\section{Effects of Openings on Flexural Strength}

The limitation on location of openings to avoid their effects was examined. In other words the locations of openings were examined so that perforated sidewalls show the same flexural performance as unperforated sidewalls. At first the effects of openings on flexural strength were examined. For this purpose two kinds of flexural strength were introduced, i.e. flexural strength of columns with perforated sidewalls and unperforated sidewalls, which could be calculated using Eqs. 2-4, simplified theoretical equations based on full plastic moment.

Shear strengths based on divided fiber sections for columns with sidewalls proposed in Ref. [1] are also shown for useful information. Figure $6 \mathrm{a}$ shows the concept of the design equation of shear strength based on divided fiber sections for columns with sidewalls. The total section is divided into two rectangular sections, i.e., side wall section and residual column section. For each section empirical design equation commonly used in practical design in Japan is applied. And the shear strength of this member can be obtained by summing these two values and the contribution of axial load as shown as Eqs. 12-14. It is added that in Ref. [1] the accuracies of the equation were examined and the equation was shown as a concervative design equation.

$$
\begin{aligned}
& Q_{s u}=r \cdot Q_{s u w}+Q_{\text {suc }}+0.1 N \\
& Q_{\text {suw }}=\left\{\frac{0.053 p_{\text {twe }}^{0.23}\left(F_{C}+18\right)}{M / Q d_{w}+0.12}+0.85 \sqrt{p_{w h} \sigma_{w h y}}\right\} t_{w} j_{w} \\
& Q_{\text {suc }}=\left\{\frac{0.053 p_{\text {tce }}^{0.23}\left(F_{C}+18\right)}{M / Q d_{c e}+0.12}+0.85 \sqrt{p_{c w e} \sigma_{c w y}}\right\} b_{c e} j_{c e}
\end{aligned}
$$

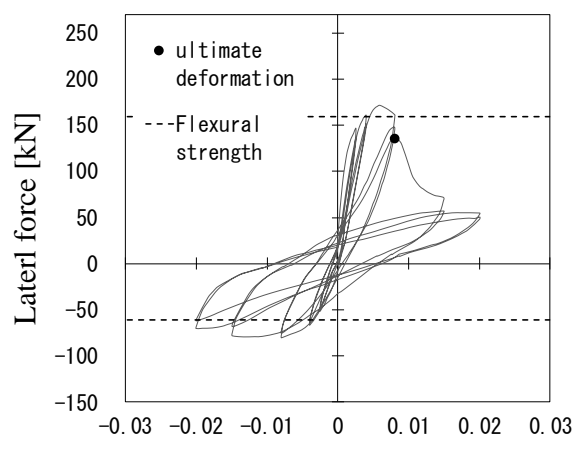

Lateral drift angle [\%]

(a)F-U

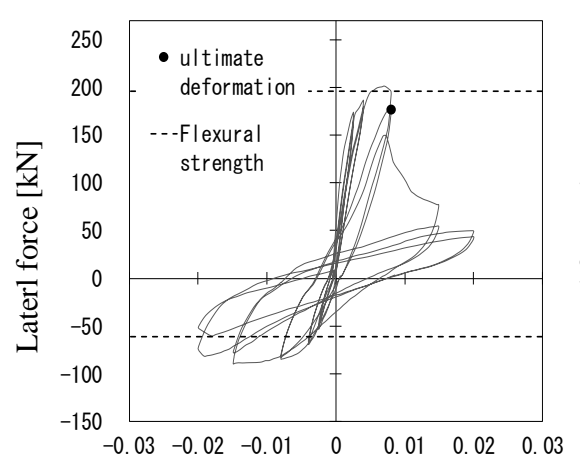

Lateral drift angle [\%]

(d)F-100D

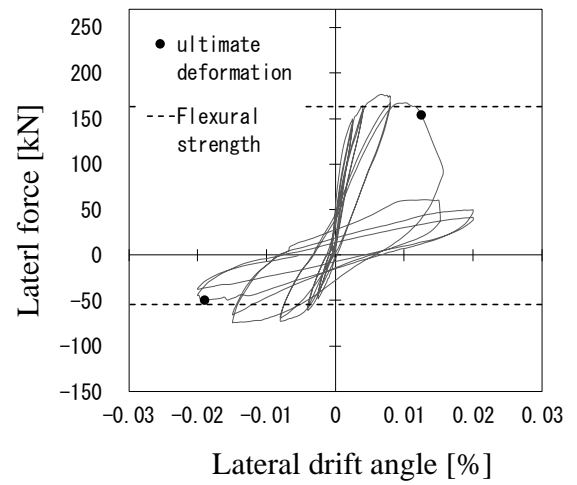

(g)F-100MC-1800

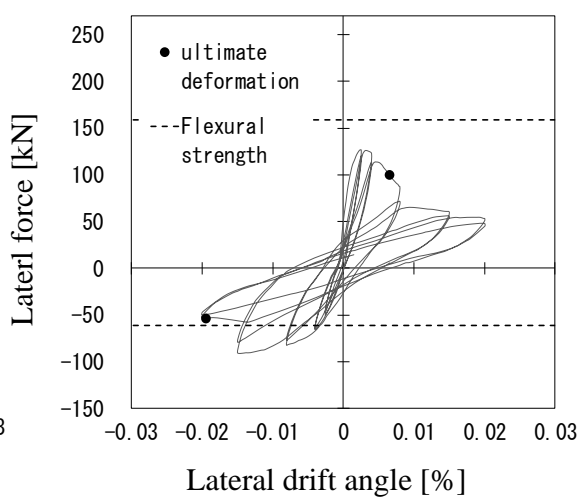

(b)F-D

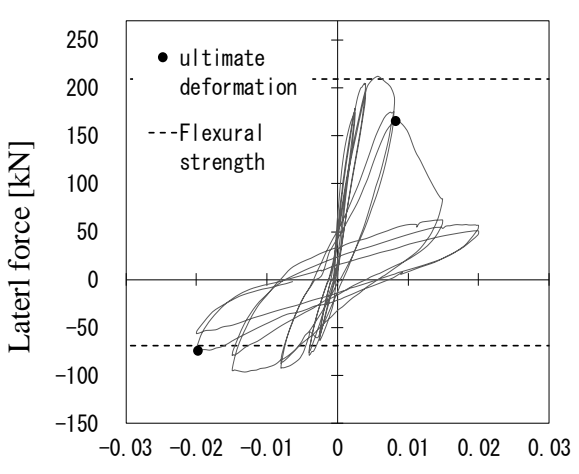

Lateral drift angle [\%]

(e)F-100M
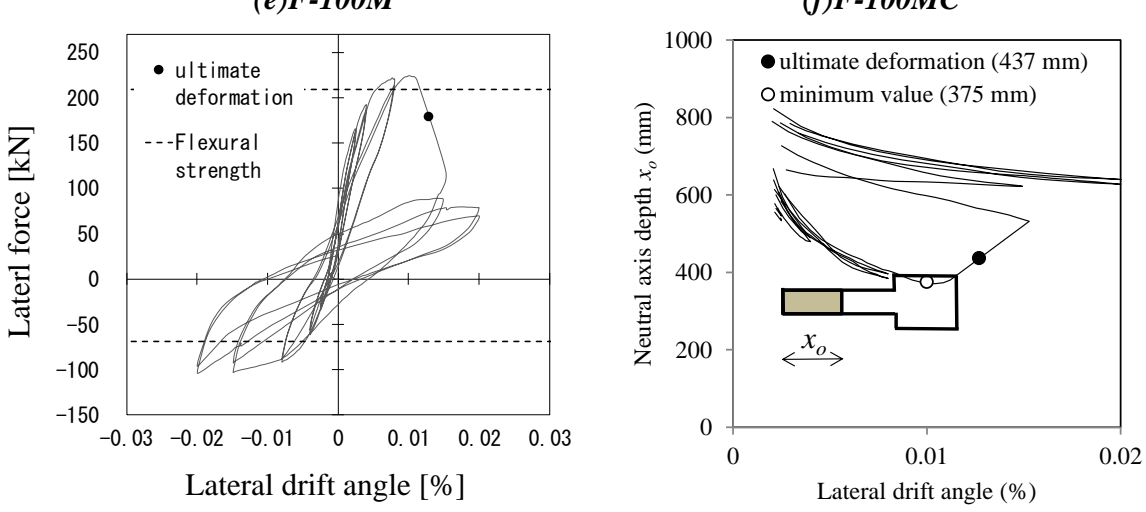

(h) $\boldsymbol{F}$

(Lateral load-lateral drift relations and observed neutral axis depth)

Figure 4: Lateral load-lateral drift relations. 


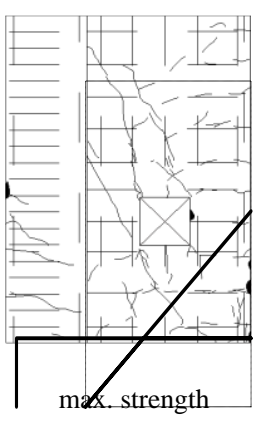

$(\mathrm{R}=0.8 \%)$

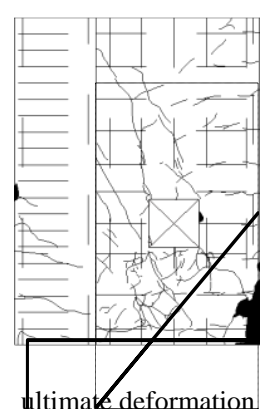

$(\mathrm{R}=1.5 \%)$

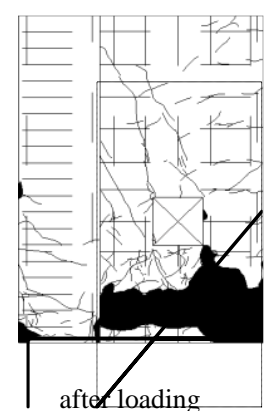

( $\mathrm{R}=2 \%)$

(a)F-U (loading direction

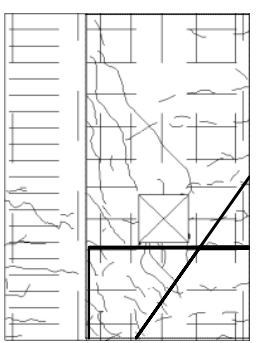

max. strength

$(\mathrm{R}=0.8 \%)$

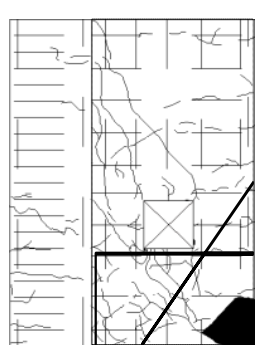

ultimate deformation $(\mathrm{R}=1.5 \%)$

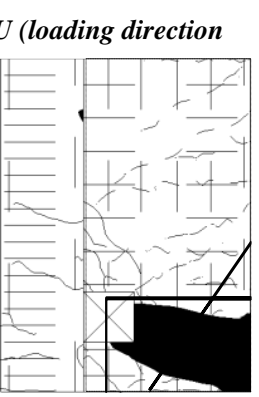

ultimate deformation

$$
(\mathrm{R}=1.5 \%)
$$

$(\mathrm{R}=0.8 \%)$

(e) F-100M (loading direction

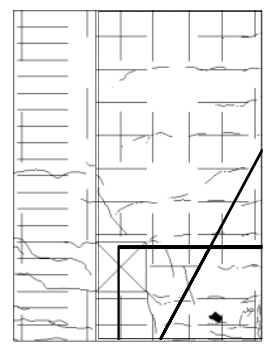

max. strength

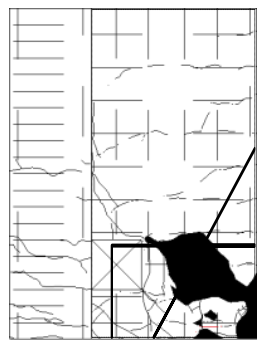

$(\mathrm{R}=0.8 \%)$

ultimate deformation

$(\mathrm{R}=1.5 \%)$

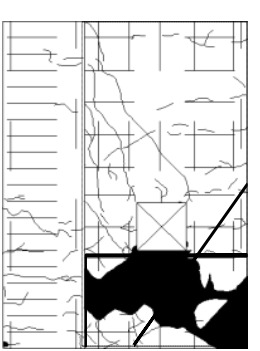

after loading

$(\mathrm{R}=2 \%)$

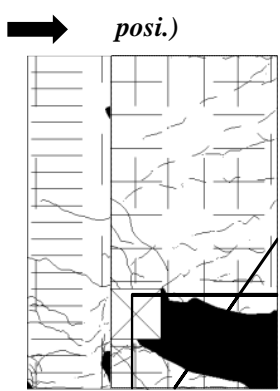

after loading

$(\mathrm{R}=2 \%)$

posi.)

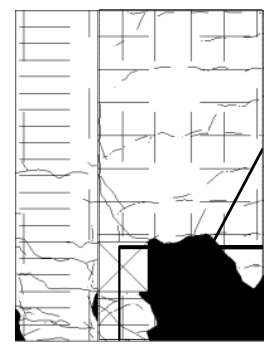

after loading

$(\mathrm{R}=2 \%)$

(g)F-100MC-1800 (loading direction

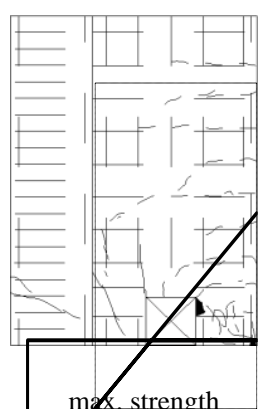

$(\mathrm{R}=0.4 \%)$

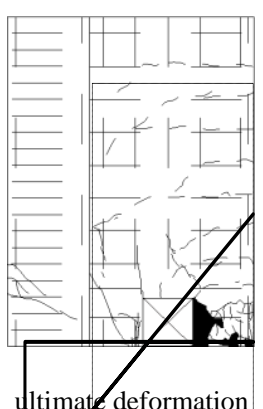

$(\mathrm{R}=0.8 \%)$

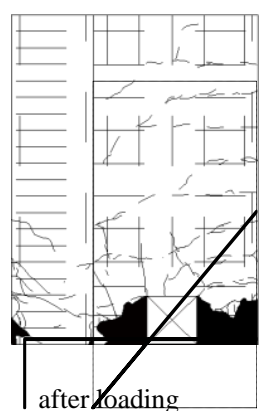

$(\mathrm{R}=2 \%)$

(b)F-D (loading direction $\longrightarrow$ posi.)

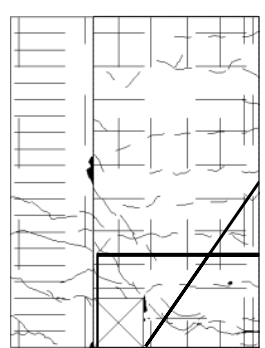

max. strength

$(\mathrm{R}=0.8 \%)$

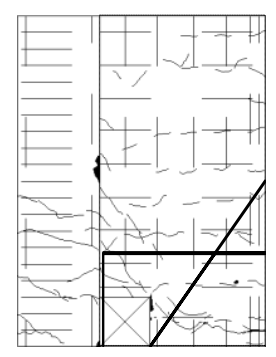

ultimate deformation

$(\mathrm{R}=0.8 \%)$

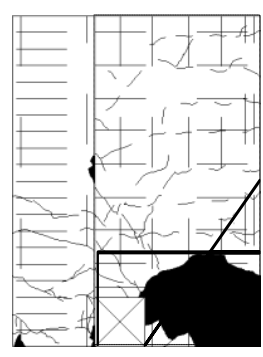

after loading

$(\mathrm{R}=2 \%)$

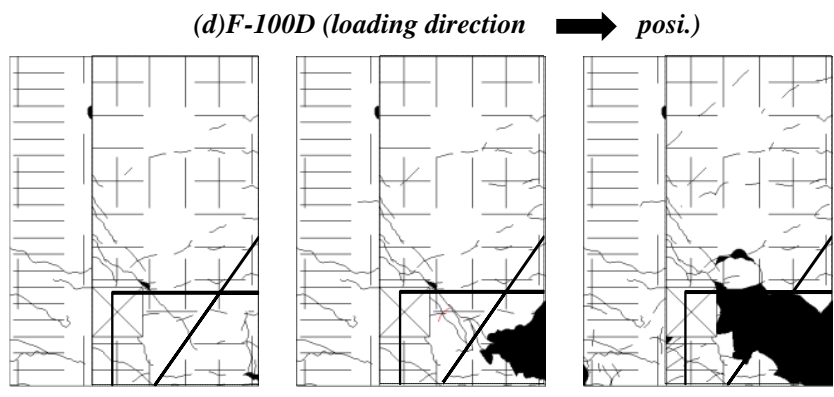

max. strength

$(\mathrm{R}=0.8 \%)$

ultimate deformation

$(\mathrm{R}=1.5 \%)$

after loading

$(\mathrm{R}=2 \%)$ posi.)

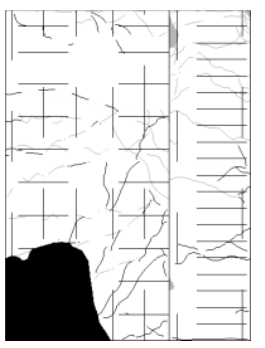

max. strength

ultimate deformation

$(\mathrm{R}=1.5 \%)$

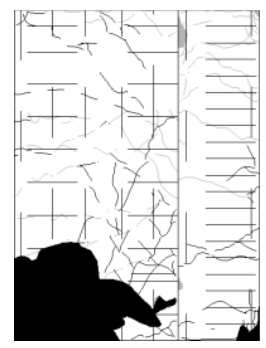

after loading

$(\mathrm{R}=2 \%)$

(h)F (loading direction $\Longleftarrow$ posi)

Figure 5: Crack patterns. 
Table 2: Comparison of drifts when key damage states occurred in the sidewalls.

\begin{tabular}{|c|c|c|c|c|c|c|c|c|}
\hline specimen name & F-U & F-D & F-100U & F-100D & F-100M & F-100MC & F-100MC-1800 & $\mathrm{F}$ \\
\hline crushing of concrete & 0.004 & 0.004 & 0.008 & 0.008 & 0.004 & 0.008 & 0.008 & 0.004 \\
\hline buckling of bar & 0.015 & 0.008 & 0.015 & 0.015 & 0.008 & 0.008 & 0.01 & 0.015 \\
\hline rupture of bar & not observed & 0.015 & 0.015 & 0.015 & 0.015 & 0.015 & 0.015 & 0.015 \\
\hline
\end{tabular}

Table 3: Comparison between calculation and test results.

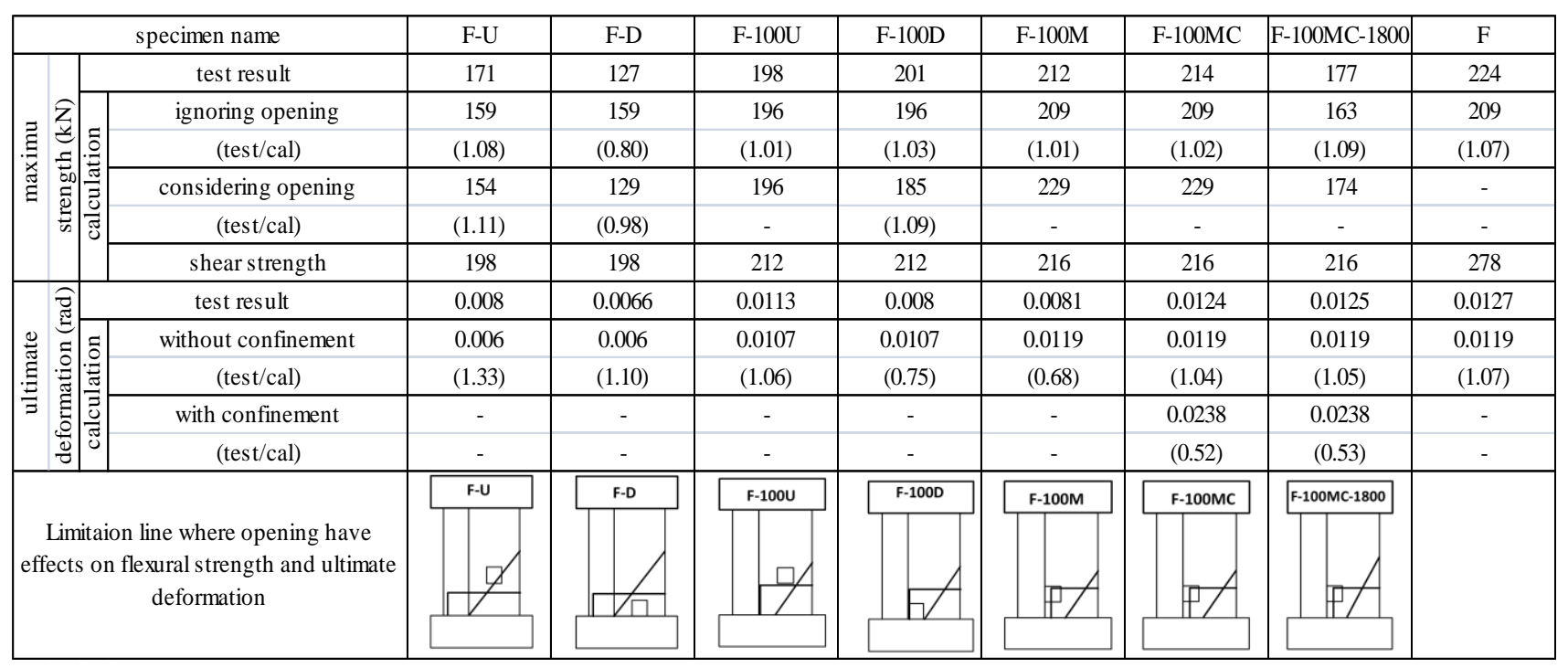

where, $F_{c}$ is concrete strength $\left(\mathrm{N} / \mathrm{mm}^{2}\right), M / Q d_{w}$ is shear span ratio, $p_{t c e}$ and $p_{t w e}$ are tensile longitudinal reinforcing ratios $(\%)$ of two divided fiber sections(\%), $p_{c w e}, \sigma_{w y}, p_{w h}$ and $\sigma_{w h y}$ are transverse reinforcing ratio and yield strength $\left(\mathrm{N} / \mathrm{mm}^{2}\right)$ of two divided fiber sections. If horizontal transverse reinforcing bars of the both side walls are not connected each other, the force of horizontal reinforcing bars should be transferred via a column hoop. So the hoop reinforcing ratio must be reduced to get the contribution of residual column fiber as shown in Figure 6b. Symbols $b_{c e}$ and $t_{w}$ are width of two divided sections, $j_{c e}$ and $j_{w}$ are effective length of two divided sections and obtained as $j_{c e}=0.95 D$ and $j_{w}=0.8 L$ (see Figure 6a).

Front part of Table 3 shows comparison of flexural strength between calculation and test results. The ratios of observed strength to calculation are also shown. Shear strengths based on divided fiber sections for columns with sidewalls calculated using Eq. 12 are also shown. Regarding shear strength it is added that all specimens failed in flexure although the shear and flexural strengths were close in some specimen (especially specimens F-100M and F-100MC). This is because the calculated shear strength was concervative as shown before.

The table indicated that calculated flexural strengths of 3 specimens F-D, F-U and F-100D were determined by flexural strength considering openings and those of other 4 specimens were determined by flexural strength ignorng openings. On the other hand test results indicated that only specimen F-D was found to not achieve the calculated flexural strength of unperforated specimens. In other words openings of specimen F-D specimens reduced the flexural strength dramatically. By the way considering from the view point of comparison with an unperforated specimen, the ratios of observed strength to calculated strength of specimens F-U (1.08) and F-100MC1800 (1.09) were comparable with an unperforated specimen $F$ (1.07), which means only these two specimens showed the same flexural performance as unperforated one.
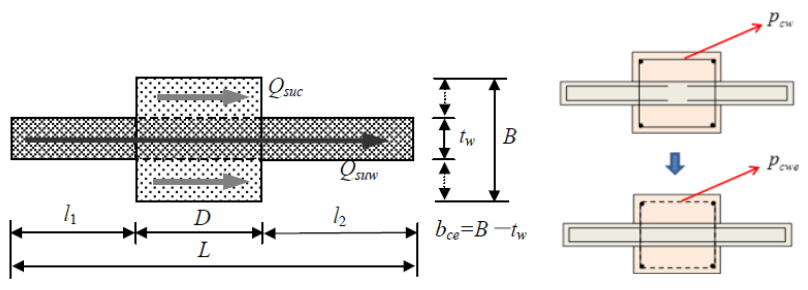

$$
p_{c w e}=\frac{a_{w}-p_{w h} t_{w} s}{b_{c e} s}
$$

(a) Divided section (b) Effective hoop reinforcement

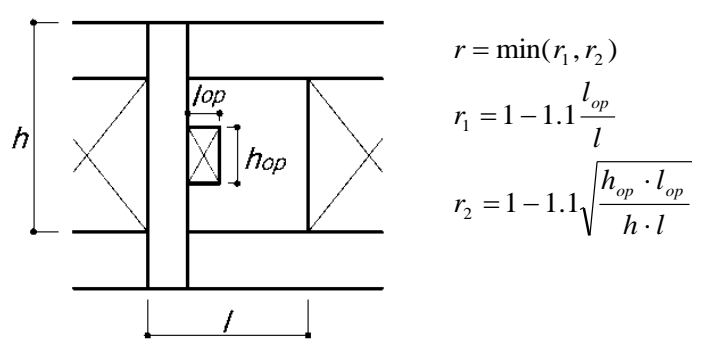

(c) Reduction factor $r$ by openings

Figure 6: Design equation of shear strength based on divided fiber sections for columns with sidewalls ${ }^{1)}$.

\section{Effects of Openings on Deformation Capacity}

Equation 15 represents design equation of ultimate deformation based on flexural theory proposed in Ref. [1] for columns with unperforated sidewalls. As for deformation capacity of RC members two types of deformation capacity must be considered, i.e. deformation capacity determined by flexure as shown by Eq. 15 and that determined by shear. But the effect of flexure on ultimate deformation is much higher than that of shear because the width of side wall is thin. So the 
ultimate deformation is generally determined by compressive failure of concrete at the edge of the sidewall.

Assuming the ultimate compressive strain of concrete " $\varepsilon_{c u}$ " and the height of compressive zone " $l h$ ", ultimate deformation $R_{u}$ based on the simplified flexural theory can be obtained using this equation. It must be noted that coefficient $c$ is an empirically obtained value to get the validity of this equation using experimental data.

$$
\begin{aligned}
& R_{u}=c \times l_{h} \times \phi_{u} \\
& c=6, \quad l_{h}=2 t, \quad \phi_{u}=\varepsilon_{c u} / x_{n} \\
& \varepsilon_{c u}= \begin{cases}0.006 & \text { (case that edge portion of sidewall is } \\
0.003 & \text { (other case) }\end{cases}
\end{aligned}
$$

Middle part of Table 3 shows comparison of ultimate deformation between calculation and test results. The ratios of observed ultimate deformation to calculation are also shown. Where, both values of 0.03 (case that edge portion of sidewall is confined less than $0.6 \%$ ) and 0.06 (case more than $0.6 \%$ ) were applied as the ultimate compressive strain of concrete $\varepsilon_{c u}$ for confined specimens F-100MC and F-100MC-1800. This is because the edge portion of these two specimens were confined by tie reinforcement, the smaller value of which was $0.46 \%$ (see Table 1). Assuming the value of 0.06 as $\varepsilon_{c u}$ for confined specimens, test results indicated that specimens except for specimens F-U and F-100U were found to not achieve the calculated deformation capacities of unperforated specimens, and this was also an effect of openings. It is noted that observed ultimate deformation of specimen F-D was larger than calculation but this is meaningless because this specimen could not achieve the calculated flexural strength as shown before.

\section{Summaries of Effects of Openings on Flexural Strength and Deformation Capacity}

In Table 3 the ratios of observed strength and ultimate deformation to calculation are shown. If these values are more than 1, this means effects of opening were not observed. Regarding flexural strength specimens F-U and F-100MC1800 were found to show the same performance as the unperforated specimens as shown before. Also regarding deformation capacity, if the value of 0.06 as $\varepsilon_{c u}$ for confined specimens is assumed test results indicated that specimens $\mathrm{F}$ $\mathrm{U}$ and $\mathrm{F}-100 \mathrm{U}$ were found to show the same performance as the unperforated specimens.

On the other hand in the bottom part of the table boundary lines of areas where openings have effects on flexural strength and deformation capacity shown in Figure 1c are drawn. So it can be concluded that these boundary lines can roughly explain the results and can be effective for practical design.

\section{CONCLUDING REMARKS}

(1) Experimental studies were reported using reinforced concrete columns with a perforated sidewall failing in flexure to examine the effects of openings on flexural strength and deformation capacity of columns with sidewalls.

(2) The limitation on location of openings perforated inside sidewalls to avoid their effects was proposed using design equations for flexural strength based on full plastic moment. In other words the locations of openings were examined so that perforated sidewalls showed the same flexural performance as unperforated sidewalls. The test results indicated that the proposed limitation line on location of openings to avoid their effects for flexure could be effective for practical design.

(3) However further examinations are necessary as for evaluating equation for ultimate deformation. Regarding Eq. (15) the empirical vales of $c$, height of compressive concrete $h_{p}$, the maximum strain $\varepsilon_{c u}$ and effective coefficient $k\left(k_{p}\right)$ for concrete are important. Furthermore, the test results can be discussed with a variety of previous studies on ultimate flexural deformation of slender walls.

(4) For case that openings are located inside the limitation area, it is also necessary to accurately estimate the strength and deformation capacity decrease due to the openings at different location for a further study.

\section{REFERENCES}

1 Architectural Institute of Japan (2016). "AIJ Standard for Lateral Load-carrying Capacity Calculation of Reinforced Concrete Structures (Draft)". AIJ, Tokyo, (in Japanese).

2 Honda Y, Sakaue M, Higuma T and Kato D (2015). "Evaluation Method for Shear Strength of R/C Column with a Side Wall with an Opening". Proceedings of the JCI Annual Convention, Chiba, Japan, 37(2): 25-30 (in Japanese).

3 Watanabe T, Nakamura T, Tamura R and Kato D (2014). "Static tests of R/C columns failing in Flexure with a side wall with an opening". Proceedings of the JCI Annual Convention, Takamatsu, Japan, 36(2): 283-288 (in Japanese).

4 Takamatsu T, Watanabe T, Tamura R and Kato D (2015). "Experimental study on effects of opening position on flexural behavior of RC columns with a side wall". Proceedings of the JCI Annual Convention, Chiba, Japan, 37(2): 115-120 (in Japanese).

5 Sato D, Takamatsu T, Kobayashi M and Kato D (2016). "Tests of RC Columns with Opened Sidewall Failing in Flexure varying Confinement of Sidewall and Shear Span". Proceedings of the JCI Annual Convention, Hakata, Japan, 38(2): 139-144 (in Japanese). 